\title{
Association of cardiac and renal function with extreme N-terminal fragment Pro-B-type natriuretic peptide levels in elderly patients
}

\author{
Hua Cui ${ }^{\dagger}$, Guoliang Huo ${ }^{\dagger}$, Lin Liu, Li Fan ${ }^{*}$, Ping Ye, Jian Cao, Yongyi Bai, Fan Wang and Yixin Hu
}

\begin{abstract}
Background: The data are inconsistent regarding whether extreme N-terminal fragment pro-B-type natriuretic peptide (NT pro-BNP) levels are associated with impaired renal function. Furthermore, the relationship between extreme NT pro-BNP levels and cardiac and renal function in elderly patients has not been reported. The aim of the present study was to examine a hypothesis that extreme NT pro-BNP levels may be associated with impaired cardiac and renal function in elderly patients.

Methods: We retrospectively analyzed the data of demographic, clinical, and echocardiographic features on 152 consecutive elderly patients aged more than 80 years old (average age, $83.65 \pm 3.58$ years) with NT pro-BNP levels $\geq 3000 \mathrm{pg} / \mathrm{ml}$. The participants were divided into two categories according to their NT pro-BNP levels: (1) $3000-10000 \mathrm{pg} / \mathrm{mL}$ and (2) $>10000 \mathrm{pg} / \mathrm{mL}$.

Results: The number of patients with impaired renal function $(P=0.019)$ and the mortality $(P<0.001)$ in the period of inpatient was higher in the group with NT pro-BNP $>10000 \mathrm{pg} / \mathrm{mL}$. The levels of serum creatinine and creatine kinase MB (CK-MB) in the group of NT pro-BNP $>10000 \mathrm{pg} / \mathrm{mL}$ were higher than those in the group of NT pro$B N P=3000-10000 \mathrm{pg} / \mathrm{mL}(P=0.001$ and $P=0.023$, respectively). Furthermore, no significant difference in the distribution by NYHA class in different NT pro-BNP levels was observed. Multiple linear regression analyses demonstrated that with NT pro-BNP levels as the dependent variable, NT pro-BNP levels were positively correlated with CK-MB $(\beta=0.182, P=0.024)$ and creatinine levels $(\beta=0.281, P=0.001)$. The area under the receiver-operating characteristic (ROC) curve of NT pro-BNP levels and clinical diagnosis of impaired renal function was 0.596 and reached significant difference ( $95 \% \mathrm{Cl}: 0.503-0.688, \mathrm{P}=0.044)$.
\end{abstract}

Conclusion: These data suggest that the extreme elevation of NT pro-BNP levels ( $\geq 3000 \mathrm{pg} / \mathrm{ml}$ ) is mainly determined by impaired renal function in elderly patients above 80 years. Extreme NT pro-BNP levels may be useful for assessing the severity of impaired renal function.

Keywords: NT pro-BNP, Factors, Elderly, Impaired renal function

\section{Background}

B-type natriuretic peptide (BNP; 77-108 amino acids) and its N-terminal (1-76 amino acids) counterpart, NTproBNP, are cardiac biomarkers that have been established for the assessment of left ventricular dysfunction and congestive heart failure. Respecting NT pro-BNP has a longer half-life than BNP, measurements of circulating levels of

\footnotetext{
* Correspondence: fanli301301@yahoo.com.cn

${ }^{\dagger}$ Equal contributors

Second Geriatric Cardiology Division, Chinese PLA General Hospital, No 28 Fuxing Road, Beijing 100853, P. R. China
}

NT pro-BNP have been prior recommended in the diagnosis and prognosis of patients with symptoms of left ventricular dysfunction [1-3]. In addition, NT pro-BNP testing is also important in the diagnostic and prognostic evaluation of patients with Chronic kidney disease (CKD) [4]. However, Law et al. [5] revealed that extreme values of BNP were not associated with kidney dysfunction or the presence of HF, cardiomyopathy. Interestingly, Guglin et al. [6] demonstrated extremely high BNP levels (4000$20,000 \mathrm{pg} / \mathrm{mL}$ ) were correlated with renal dysfunction measured by serum creatinine levels. 
CKD is regarded as an important problem in elderly patients, which is an independent risk factor for cardiovascular disease. The prevalence of CKD rises rapidly in individuals older than 60 years of age [7]. It is well documented that adults lose about $1 \mathrm{~mL} / \mathrm{min} / \mathrm{y}$ of the glomerular filtration rate (GFR) from the age of 40 to 45 years. Given the increased incidence of impaired renal function and NT pro-BNP levels in elderly patients [8], we hypothesized that extreme NT pro-BNP levels may be associated with impaired renal function in elderly patients. Furthermore, the relationship between extreme NT pro-BNP levels and cardiac and renal function in elderly patients has not been reported. The aim of the present study was to examine the hypothesis that extreme NT pro-BNP levels may be associated with impaired cardiac and renal function in elderly patients.

\section{Methods}

\section{Ethical approval of the study protocol}

This study complied with the Declaration of Helsinki. It was approved by the Scientific and Ethics Review Board of the Department of Geriatrics, Chinese PLA General Hospital (Beijing, PR China). All patients provided written informed consent to be included in the study.

\section{Participants}

We screened for elderly patients $\geq 80$ years, hospitalized between April 2010 and January 2011, whose NT proBNP values were $\geq 3000 \mathrm{pg} / \mathrm{mL}$ regardless of diagnosis. According to the NT pro-BNP levels, the patients were divided into two categories: $3000-10000 \mathrm{pg} / \mathrm{mL}$ and $>10000 \mathrm{pg} / \mathrm{mL}$. The cutoff of NT pro-BNP level was chosen arbitrarily.

NT pro-BNP was determined by chemiluminescence immunoassay, ADVIA Centaur ${ }^{\mathrm{rw}}$ system (Roche Inc.), and was expressed as $\mathrm{pg} / \mathrm{ml}$. The normal value for the NT pro-BNP test was $<150 \mathrm{pg} / \mathrm{mL}$. From the values $>3000 \mathrm{pg} / \mathrm{mL}$ measured during the same hospital admission, we calculated the average number. Laboratory indicators, such as C-reactive protein (CRP), albumin, creatine kinase $\mathrm{MB}$ (CK-MB) and creatinine levels, which may be correlated with the NT pro-BNP level, were also collected on the same day when NT pro-BNP exceeded $3000 \mathrm{pg} / \mathrm{mL}$.

We reviewed medical records of all patients enrolled, including history and physical examination findings, progress notes and the data of instrumental and laboratory diagnostic tests. From the clinical records available, we made the diagnosis of heart failure (HF) and estimated functional class by the New York Heart Association (NYHA).

Left ventricular ejection fraction (LVEF) was calculated by means of echocardiographic study using Simpson's rule. Other parameters of structural and functional of heart, such as left atrial diameter, right atrial diameter, interventricular septum, posterior wall, left ventricular end systolic diameter (LVESD) and left ventricular end diastolic diameter (LVEDD), fractional shortening (FS) were also reviewed from electronic medical records closed to the day when NT pro-BNP exceeded $3000 \mathrm{pg} /$ $\mathrm{mL}$. Serum creatinine levels were recorded on the same day that NT pro-BNP exceeded $3000 \mathrm{pg} / \mathrm{mL}$. Impaired renal function was defined as a serum creatinine level $>1.5 \mathrm{mg} / \mathrm{dL}[9]$.

\section{Statistical analysis}

Results are presented as mean $\pm \mathrm{SD}$, as median and interquartile ranges, or as percentages and numbers for categorical data. Normality and homogeneity of variances were tested for all variables. NT pro-BNP was natural logarithmically transformed to normalize their distributions. The Student's t-test or Mann-Whitney U two-sample tests (if the distribution was not normal) were used to compare the continuous variables between the two groups. Categorical data and proportions were analyzed using the Mann-Whitney U or kruskal Wallis $\mathrm{H}$ test where appropriate. Variables potentially associated with the plasma concentration of NT pro-BNP in all subjects were analyzed by linear regression analyses. The relationship between NT pro-BNP and clinical diagnosis of HF or impaired renal function was tested with the area under the receiver-operating characteristic (ROC) curve. $\mathrm{P}<0.05$ was considered statistically significant. All analyses were performed using SPSS for Windows version 16.0 (SPSS, Chicago, IL, USA).

\section{Results}

\section{Patient characteristics}

Demographics are provided in Table 1. One hundred and fifty-two consecutive patients $(91 \mathrm{men}$ and 61 women) with an age ranging from 80 to 94 (mean age, $83.65 \pm 3.58 \mathrm{yr}$ ) were enrolled and underwent statistical analysis. Among them, the NT pro-BNP levels of 108 patients (66 men) were between $3000 \mathrm{pg} / \mathrm{mL}$ and $10000 \mathrm{pg} / \mathrm{mL}$ (group A), 44 (25 men) $\geq 10000 \mathrm{pg} / \mathrm{mL}$ (group B). Of the 152 participants, 16 patients admitted with acute myocardial infarction, 69 with HF or HF exacerbation, and 24 patients died during their hospitalization. Among 83 patients without HF symptoms, the main reason of being hospitalized, including infections (35 patients); brain damage such as stroke and Parkinson's disease (11 patients); cancer (25 patients); and miscellaneous conditions (remaining 12 patients).

There were no significant differences between the group A and the group B, when comparing age; having atrial fibrillation, diabetes mellitus, hypertension, cancer, chronic obstructive pulmonary disease or liver diseases; echocardiographic parameters; and medications. More patients with impaired renal function $(\mathrm{P}=0.019)$ and 
Table 1 Baseline characteristics of the enrolled patients with elevated NT pro-BNP levels

\begin{tabular}{|c|c|c|c|}
\hline & $\begin{array}{l}\text { NT pro-BNP } 3000-10000 \mathrm{pg} / \mathrm{mL} \\
\text { (group } \mathrm{A}, \mathrm{n}=108 \text { ) }\end{array}$ & $\begin{array}{l}\text { NT pro-BNP } \geq 10000 \mathrm{pg} / \mathrm{mL} \\
\text { (group } \mathrm{B}, \mathrm{n}=44 \text { ) }\end{array}$ & $P$ \\
\hline Age (years) & $83.57 \pm 3.33$ & $83.84 \pm 4.18$ & 0.679 \\
\hline Male, n (\%) & $66(61.1)$ & $25(56.8)$ & 0.625 \\
\hline BMI (kg/m2) & $22.64 \pm 3.79$ & $21.50 \pm 3.33$ & 0.084 \\
\hline $\mathrm{SBP}(\mathrm{mm} \mathrm{Hg})$ & $126.69 \pm 20.21$ & $128.39 \pm 23.19$ & 0.653 \\
\hline $\mathrm{DBP}(\mathrm{mm} \mathrm{Hg})$ & $68.25 \pm 12.37$ & $66.32 \pm 16.54$ & 0.487 \\
\hline \multicolumn{4}{|c|}{ Underlying commodities disease, n (\%) } \\
\hline Coronary artery disease & $89(82.4)$ & $37(84.1)$ & 0.803 \\
\hline Atrial fibrillation & 43(39.8) & 15(84.1) & 0.447 \\
\hline Diabetes mellitus & $37(34.3)$ & 19(43.2) & 0.303 \\
\hline Hypertension & $81(75.0)$ & $36(81.8)$ & 0.367 \\
\hline COPD & 13(12.0) & $4(99.1)$ & 0.602 \\
\hline Respiratory failure & 13(12.0) & 7(15.9) & 0.523 \\
\hline Cancer & $29(26.9)$ & $10(22.7)$ & 0.860 \\
\hline Liver disease & $10(9.3)$ & $5(11.4)$ & 0.694 \\
\hline MODS & $6(5.6)$ & $1(2.3)$ & 0.383 \\
\hline Impaired renal function & $39(36.1)$ & $25(56.8)$ & 0.019 \\
\hline Infection & $57(52.8)$ & 28(63.6) & 0.223 \\
\hline Acute myocardial infarction & $7(6.5)$ & $4(9.1)$ & 0.951 \\
\hline Death & $9(8.3)$ & $15(34.1)$ & $<0.001$ \\
\hline \multicolumn{4}{|l|}{ Echocardiographic parameters } \\
\hline LVEF (\%) & $54.88 \pm 10.44$ & $53.41 \pm 9.98$ & 0.427 \\
\hline Left atrial diameter (mm) & $39.39 \pm 6.43$ & $38.07 \pm 5.34$ & 0.231 \\
\hline Right atrial diameter (mm) & $37.81 \pm 6.85$ & $36.39 \pm 5.22$ & 0.216 \\
\hline Interventricular septum (mm) & $10.69 \pm 1.57$ & $10.80 \pm 1.75$ & 0.729 \\
\hline Posterior wall (mm) & $10.06 \pm 1.28$ & $10.14 \pm 1.75$ & 0.753 \\
\hline LV diastolic dimension (mm) & $49.98 \pm 6.51$ & $50.55 \pm 5.42$ & 0.613 \\
\hline LV systolic dimension (mm) & $35.67 \pm 6.41$ & $35.93 \pm 5.74$ & 0.265 \\
\hline Fractional shortening (\%) & $29.81 \pm 5.72$ & $29.20 \pm 4.79$ & 0.297 \\
\hline \multicolumn{4}{|l|}{ Laboratory data } \\
\hline Creatinine (mg/dL) & $1.24(0.92-1.82)$ & $1.39(0.91-4.57)$ & 0.001 \\
\hline CK-MB (ng/dL) & $2.5(0.90-368)$ & $3.63(1.72-5.77)$ & 0.023 \\
\hline Serum albumin(g/dL) & $33.44 \pm 5.11$ & $32.83 \pm 6.76$ & 0.540 \\
\hline C-reactive protein (mg/dL) & $3.07(0.86-7.58)$ & $3.44(1.025-8.6)$ & 0.375 \\
\hline \multicolumn{4}{|l|}{ Medication, n (\%) } \\
\hline ACEls or ARBs & $7(6.5)$ & $20(45.5)$ & 0.803 \\
\hline$\beta$-blockers & 16(36.4) & $48(44.4)$ & 0.362 \\
\hline
\end{tabular}

NT pro-BNP, N-terminal fragment pro-B-type natriuretic peptide;NS, not significant; BMI, body mass index; SBP, Systolic blood pressure; DBP, diastolic blood pressure ; $\mathrm{HF}$, heart failure; $\mathrm{LV}$, left ventricular; MODS, multiple organ dysfunction syndrome; CK-MB, MB isoenzyme of creatine kinase; COPD, chronic obstructive pulmonary disease. Data were shown as mean \pm SD, percentages and median values (quartile 1, quartile 3) for different parameters.

higher mortality $(\mathrm{P}<0.001)$ in the period of hospitalization were found in the group B when compared to group A. The levels of serum creatinine and the CK-MB in the group $B$ were higher than that in the group A $(\mathrm{P}=0.001, \mathrm{P}=0.023$ respectively $)$, but no difference trend appeared in serum albumin and Creactive protein between the two groups.

No significant difference in the distribution by NYHA class in different NT-pro BNP levels was observed between the group A and B presented in Table 2. 
Table 2 Distribution patients by NYHA class in different NT pro-BNP Levels

\begin{tabular}{|c|c|c|}
\hline & $\begin{array}{l}\text { NT pro-BNP } 3000-10000 \\
(\mathrm{pg} / \mathrm{mL}, \%) \\
\text { (group } \mathrm{A}, \mathrm{n}=108 \text { ) }\end{array}$ & $\begin{array}{l}\text { NT pro-BNP } \geq 10000 \\
(\mathrm{pg} / \mathrm{mL}, \%) \\
\text { (group } \mathrm{B}, \mathrm{n}=44 \text { ) }\end{array}$ \\
\hline NYHAI & $23(21)$ & 7 (16) \\
\hline NYHAII & $36(34)$ & $13(30)$ \\
\hline NYHAIII & 31 (38) & $15(34)$ \\
\hline NYHAIV & $18(17)$ & $9(20)$ \\
\hline
\end{tabular}

NYHA, New York Heart Association class; NT pro-BNP, N-terminal fragment proB-type natriuretic peptide.

\section{Correlation and ROC analyses}

Correlation analyses showed that NT pro-BNP levels were positively correlated with CK-MB ( $\mathrm{r}=0.162$, $\mathrm{P}=0.050)$ and creatinine $(\mathrm{r}=0.237, \mathrm{P}=0.003)$. Multiple linear regression analyses demonstrated that with NTpro BNP levels as the dependent variable, NT pro-BNP levels were positively correlated with CK-MB $(\beta=0.182$, $\mathrm{P}=0.024)$ and creatinine $(\beta=0.281, \mathrm{P}=0.001)$ (Table 3 ). The area under the ROC curve of NT pro-BNP levels and clinical diagnosis of HF was 0.582 and was not significant (95\%CI:0.474-0.690, $\mathrm{p}=0.164) \quad$ (Figure 1).

Table 3 Correlation between clinical data, echocardiographic parameters, laboratory data and NT pro-BNP levels

\begin{tabular}{|c|c|c|c|c|}
\hline & \multicolumn{2}{|c|}{ Univariate } & \multicolumn{2}{|c|}{ Multivariate } \\
\hline & $r$ & $P$ & $\beta$ & $P$ \\
\hline Age & -0.017 & 0.832 & - & NS \\
\hline BMI & -0.134 & 0.099 & -0.151 & 0.058 \\
\hline Systolic blood pressure & -0.029 & 0.726 & - & NS \\
\hline Diastolic blood pressure & -0.122 & 0.134 & - & NS \\
\hline \multicolumn{5}{|c|}{ Echocardiographic parameters } \\
\hline LVEF & -0.085 & 0.300 & - & NS \\
\hline Left atrial diameter & -0.031 & 0.701 & - & NS \\
\hline Right atrial diameter & -0.093 & 0.254 & - & NS \\
\hline Interventricular septum & -0.078 & 0.341 & - & NS \\
\hline Posterior wall & -0.022 & 0.787 & - & NS \\
\hline LV diastolic dimension & 0.054 & 0.512 & - & NS \\
\hline LV systolic dimension & 0.028 & 0.730 & - & NS \\
\hline Fractional shortening & 0.012 & 0.883 & & NS \\
\hline \multicolumn{5}{|l|}{ Laboratory data } \\
\hline Creatinine & 0.237 & 0.003 & 0.281 & 0.001 \\
\hline CK-MB & 0.162 & 0.050 & 0.182 & 0.024 \\
\hline Serum albumin, & -0.078 & 0.337 & - & NS \\
\hline C-reactive protein & 0.131 & 0.341 & - & NS \\
\hline
\end{tabular}

NT pro-BNP, N-terminal fragment pro-B-type natriuretic peptide; NS, not significant; BMI, body mass index; SBP, systolic blood pressure; DBP, diastolic blood pressure; $\mathrm{HF}$, heart failure; LV, left ventricular; CK-MB, MB isoenzyme of creatine kinase.
However, the area under the ROC curve of NT pro-BNP levels and clinical diagnosis of impaired renal function was 0.596 and reached significant difference (95\% CI:0.503-0.688, $\mathrm{p}=0.044$ ) (Figure 1).

\section{Discussion}

In the present study, we found extreme NT pro-BNP levels were positively correlated with creatinine levels and the evaluation of impaired renal function in elderly patients. Elevated NT pro-BNP levels are common in patients with CKD, as it showed in the presence of coronary artery disease (CAD) and left ventricular hypertrophy (LVH). Nitta and colleagues [10] reported that the mean serum NT pro-BNP concentration was higher in haemodialysis patients than in normal healthy subjects. Yang et al. [11] demonstrated that BNP levels of patients with CKD showed a positive correlation with creatinine levels, and a high concentration of BNP can be seen in patients with stage 5 CKD without heart failure. After analyzing 277 patients with CKD, Prnjavorac et al. [12] found that NT pro-BNP increased at the beginning of water overload in patients with CKD. However, Law et al. [5] demonstrated that BNP levels were not correlated with the presence of renal dysfunction in 113 patients with BNP value $>3000 \mathrm{pg} / \mathrm{mL}$. The major reason for this inconsistency maybe that patients with an age ranging from 21 to 102 were enrolled in Law's study, which may lead to different result regarding BNP levels determined by age. Moreover, our results are similar to the study by Guglin et al. [6], who also found high BNP levels (4000-20,000 pg/mL) were associated with kidney dysfunction. Although the data are inconsistent, our results suggest in elderly patients, the extreme NT pro-BNP may be more useful for the assessment of the severity of impaired renal function. Certainly, further studies are still needed to ascertain the relationship between extreme BNP levels and impaired renal function in large sample size.

Previous evidence demonstrated that BNP testing is a useful tool for the diagnosis or stratification of decompensated heart failure $[13,14]$. Most studies have confirmed that BNP is associated with the severity of HF in a certain range. However, a study regardless of age published in 2010 demonstrated that extreme values of BNP do not correlate with the presence of HF [15]. Our results also showed that there was no significant difference in the distribution by NYHA class and LVEF in different NT proBNP levels. There are several possible reasons for this phenomenon. Firstly, immunoassays play an important role in falsely elevating BNP levels, which are used in the clinical setting and do not determine precise molecular forms of these natriuretic peptides. A review showed antibodies against BNP may also recognize and bind to proBNP and NT-fragments [16]. Meanwhile, analysis from 

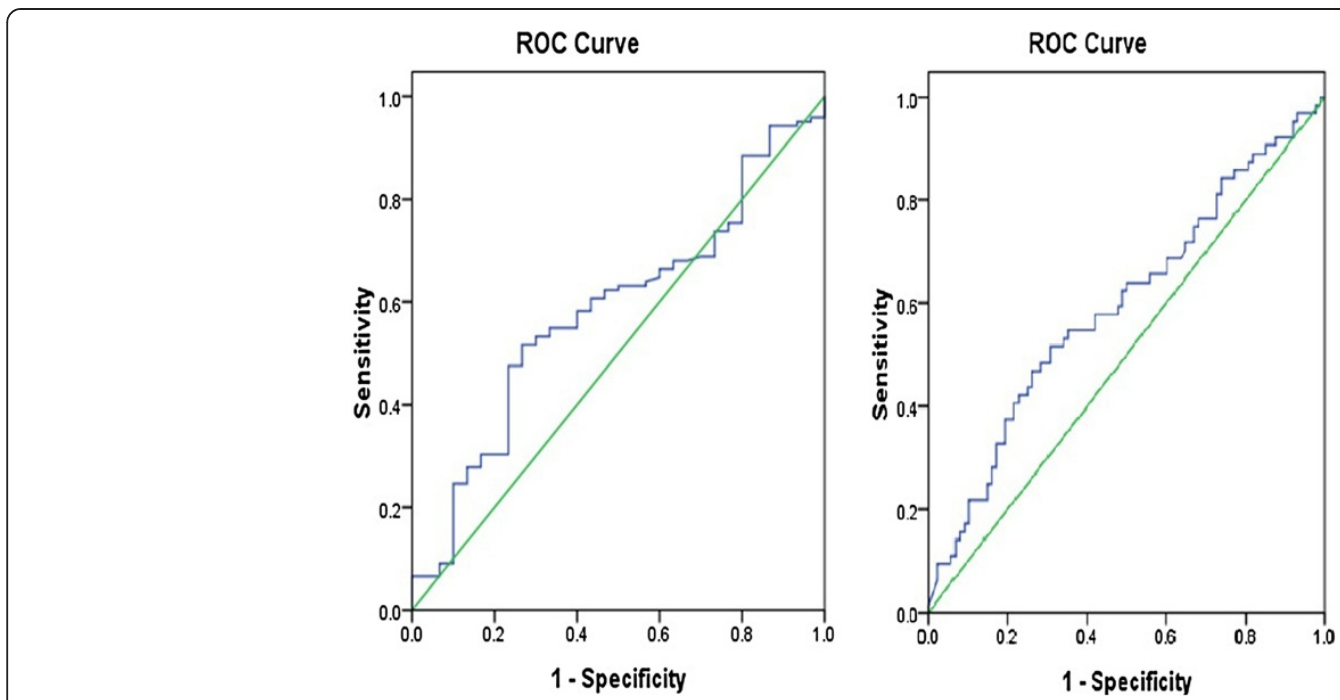

Figure 1 The ROC curve of NT pro-BNP levels and clinical diagnosis of HF (Figure A) and impaired renal function (Figure B). AUC = area under the curve; $\mathrm{Cl}=$ confidence interval; $\mathrm{ROC}=$ receiver-operating characteristic.

chromatography-based studies revealed that inactive proBNP forms often predominate in HF,. This indicates that the bioactive forms of natriuretic peptides may not be processed proportionally in patients with advanced HF. Secondly, inflammation may be associated with falsely elevating BNP levels. Because one study had demonstrated that inflammatory markers were positively correlated with BNP levels, suggesting a link between elevations of BNP levels and inflammation [17].

Through a systematic review of 19 studies, Doust and colleagues found that NT pro-BNP is a strong prognostic indicator for both asymptomatic patients and for patients with heart failure at all stages of disease, and for every $100 \mathrm{ng} / \mathrm{L}$ rise in NT pro-BNP concentration, there was a corresponding $35 \%$ increase in the relative risk of death [18]. Additionally, a previous cohort study showed that NT pro-BNP was found to be a good predictor of mortality in elderly with and without specific cardiac diagnoses [19]. Bettencourt and colleagues [20] also demonstrated that NT pro-BNP levels were the strongest independent predictor of death or hospital readmission during hospitalization and six months of follow-up. In the extremely elevated geriatric population above 80 years, we found higher levels of NT pro-BNP with higher mortality. These results confirmed that even with the level above $3000 \mathrm{pg} / \mathrm{ml}$ and suggested that NT proBNP may be also an independent predictor of death in elderly patients with or without cardiac disease.

In the early phase of AMI, NT pro-BNP gene expression increases considerably, the phenomenon also can be seen in human cardiac allograft acute rejection [21]. Therefore, NT pro-BNP is a useful marker of reflection injury of myocardium function and prognostic of myocardial infarction [22]. Moreover, NT pro-BNP level is similar to BNP in circulation of healthy volunteers and it proportionally increse as cardiac function deterioration $[23,24]$. After compared the predictive value of NT proBNP and other frequently used biomarkers, Melki et al. recently found that NT pro-BNP may be the best single predictor of left ventricular function in patients with non-ST-segment elevation acute coronary syndromes [25]. In the present study, although there was no difference in the ratio of acute myocardial infarction patients in admission in different level of NT pro-BNP, we found the weak correlation between NT pro-BNP and CK-MB, and higher levels of CK-MB accompanied with higher NT pro-BNP, suggests elevated CK-MB levels derived from AMI contribute to the elevation of NT pro-BNP.

In recent years, CRP has emerged as a possible potent risk marker for cardiovascular diseases [26,27]. The correlation between CRP and BNP levels has also been demonstrated [17], which means a possible interaction between natriuretic peptides and the systemic inflammatory response. Conversely, Caroline and collegues [28] found that CRP levels are not independently associated with first cardiovascular events in older individuals, and increasing age seems to attenuate the association between plasma CRP levels and the risk of cardiovascular disease. We also observed the levels of CRP in the study, but didn't find the correlation between NT pro-BNP and CRP.

In addition, multiple factors are known to influence the circulating levels of NT pro-BNP. The prevalence of possible influencing factors including gender, body mass index (BMI), anemia and medications for heart failure such as ACE inhibitors, angiotensin-receptor blockers, beta blockers [29-31], but in the present study, we didn't find the correlation between BNP and all of them. 
Maybe these parameters are just confounding variables, and the underlying mechanism still needs to be further revealed.

There are several limitations in the present study. Firstly, the cutoff of NT pro-BNP for the enrolment and groups was established arbitrarily. Secondly, we only enrolled elderly patients above 80 years, and the population with the characteristics of more comorbidities and more severe conditions, that bring about a more confounding factor.

\section{Conclusions}

In conclusion, our results suggest that in elderly patients above 80 years, extreme elevation of NT pro-BNP $(\geq 3000 \mathrm{pg} / \mathrm{ml}$ ) is mainly determined by impaired renal function. Extreme NT pro-BNP levels may be useful for the assessment of the severity of impaired renal function.

\section{Abbreviations}

NT pro-BNP: N-terminal fragment pro-B-type natriuretic peptide; CKMB: Creatine kinase MB; CKD: Chronic kidney disease; GFR: Glomerular filtration rate; CRP: C-reactive protein; HF: Heart failure; NYHA: New York heart association; CAD: Coronary artery disease; ROC: Receiver-operating characteristic; LVEF: Left ventricular ejection fraction; LVESD: Left ventricular end systolic diameter; LVEDD: Left ventricular end diastolic diameter; FS: Fractional shortening.

\section{Competing interests}

The authors declare that they have no competing financial or any other kind of personal interests in this paper.

\section{Authors' contributions}

HC: obtained funding, designed the study, acquired the data, analyzed the data, interpreted of the data and drafted the manuscript. GLH: Have made substantial contributions to the design, analyses, interpretation of data and drafting the manuscript. LL: Involved in drafting the manuscript and analyzing the data. LF: Have made substantial contributions to the design, obtaining grant, analyses, interpretation of data and revising the manuscript. PY: Have made substantial contributions to the design, and analyses, interpretation of data. JC: Have made substantial contributions to the design, and analyses, interpretation of data. YYB: Have made substantial contributions to the design, analyses, interpretation of data and revising the manuscript. FW: Have made substantial contributions to the design, and analyses, interpretation of data. YXH: Have made substantial contributions to the design, and analyses, interpretation of data. All authors read and approved the final manuscript.

\section{Acknowledgment and funding}

This work was supported by the Healthcare Fund 06MA290 and Fund of the Ministry of Science and Technology of China (2009BAl86B04).

Received: 19 January 2012 Accepted: 26 July 2012

Published: 26 July 2012

\section{References}

1. Levin ER, Gardner DG, Samson WK: Natriuretic peptides. N Engl J Med 1998, 339:321-328.

2. Daniels LB, Maisel AS: Natriuretic peptides. J Am Coll Cardio/ 2007, 50:2357-2368.

3. Dickstein K, Cohen-Solal A, Filippatos G, McMurray JJ, Ponikowski P, PooleWilson PA, Stromberg A, van Veldhuisen DJ, Atar D, Hoes AW, Keren A, Mebazaa A, Nieminen M, Priori SG, Swedberg K, Vahanian A, Camm J, De Caterina R, Dean V, Funck-Brentano C, Hellemans I, Kristensen SD, McGregor K, Sechtem U, Silber S, Tendera M, Widimsky P, Zamorano JL: ESC Guidelines for the diagnosis and treatment of acute and chronic heart failure 2008: the Task Force for the Diagnosis and Treatment of Acute and Chronic Heart Failure 2008 of the European Society of Cardiology. Developed in collaboration with the Heart Failure Association of the ESC (HFA) and endorsed by the European Society of Intensive Care Medicine (ESICM). Eur Heart J 2008, 29:2388-2442.

4. DeFilippi C, van Kimmenade RR, Pinto YM: Amino-terminal pro-B-type natriuretic peptide testing in renal disease. Am J Cardiol 2008, 101:82-88.

5. Law C, Glover C, Benson K, Guglin M: Extremely high brain natriuretic peptide does not reflect the severity of heart failure. Congest Heart Fail 2010, 16:221-225.

6. Guglin M, Hourani R, Pitta S: Factors determining extreme brain natriuretic peptide elevation. Congest Heart Fail 2007, 13:136-141.

7. Robinson BE: Epidemiology of chronic kidney disease and anemia. J Am Med Dir Assoc 2006, 7(9 Suppl):S3-S6. quiz S17-21.

8. Maisel AS, Clopton P, Krishnaswamy P, Nowak RM, McCord J, Hollander JE, Duc P, Omland T, Storrow AB, Abraham WT, Wu AH, Steg G, Westheim A, Knudsen CW, Perez A, Kazanegra R, Bhalla V, Herrmann HC, Aumont MC, McCullough PA: Impact of age, race, and sex on the ability of B-type natriuretic peptide to aid in the emergency diagnosis of heart failure: results from the Breathing Not Properly (BNP) multinational study. Am Heart J 2004, 147:1078-1084.

9. Coresh J, Astor BC, Greene T, Eknoyan G, Levey AS: Prevalence of chronic kidney disease and decreased kidney function in the adult US population: Third National Health and Nutrition Examination Survey. Am J Kidney Dis 2003, 41:1-12.

10. Nitta K, Kawashima A, Yumura W, Naruse M, Oba T, Kabaya T, Nihei H: Plasma concentration of brain natriuretic peptide as an indicator of cardiac ventricular function in patients on hemodialysis. Am J Nephrol 1998, 18:411-415.

11. Yang JW, Kim MS, Kim JS, Yoo JM, Han ST, Kim BR, Kim YD, Choi JW, Choi SO, Han BG: Relationship between serum brain natriuretic peptide and heart function in patients with chronic kidney disease. Korean J Intern Med 2008, 23:191-200.

12. Prnjavorac B, Abduzaimovic K, Jukic J, Sejdinovic R, Mujaric E, Irejiz N, Hadzovic-Dzuvo A, Jadric R, Causevic A, Semiz S, Bego T, Malenica M: Use of amino-terminal pro-B type natriuretic peptide as the parameter for long-term monitoring of water overload in patient with chronic kidney diseases. Med Glas Ljek komore Zenicko-doboj kantona 2011, 8:116-120.

13. Tang WH, Francis GS, Morrow DA, Newby LK, Cannon CP, Jesse RL, Storrow $A B$, Christenson RH: National academy of clinical biochemistry laboratory medicine practice guidelines: clinical utilization of cardiac biomarker testing in heart failure. Clin Biochem 2008, 41:210-221.

14. Pemberton $\mathrm{CJ}$, Johnson ML, Yandle TG, Espiner E: Deconvolution analysis of cardiac natriuretic peptides during acute volume overload. Hypertension 2000, 36:355-359.

15. Liang F, O'Rear J, Schellenberger U, Tai L, Lasecki M, Schreiner GF, Apple FS, Maisel AS, Pollitt NS, Protter AA: Evidence for functional heterogeneity of circulating B-type natriuretic peptide. J Am Coll Cardiol 2007, 49:1071-1078

16. Xu-Cai YO, Wu Q: Molecular forms of natriuretic peptides in heart failure and their implications. Heart 2009, 96:419-424.

17. Rudiger A, Gasser S, Fischler M, Hornemann T, von Eckardstein A, Maggiorini M: Comparable increase of B-type natriuretic peptide and amino-terminal proB-type natriuretic peptide levels in patients with severe sepsis, septic shock, and acute heart failure. Crit Care Med 2006, 34:2140-2144.

18. Doust JA, Pietrzak E, Dobson A, Glasziou P: How well does B-type natriuretic peptide predict death and cardiac events in patients with heart failure: systematic review. BMJ 2005, 330:625.

19. Vaes B, de Ruijter W, Degryse J, Westendorp RG, Gussekloo J: Clinical relevance of a raised plasma $\mathrm{N}$-terminal pro-brain natriuretic peptide level in a population-based cohort of nonagenarians. J Am Geriatr Soc 2009, 57:823-829.

20. Bettencourt P, Azevedo A, Pimenta J, Frioes F, Ferreira S, Ferreira A: Nterminal-pro-brain natriuretic peptide predicts outcome after hospital discharge in heart failure patients. Circulation 2004, 110:2168-2174.

21. Ogawa T, Veinot JP, Davies RA, Haddad H, Smith SJ, Masters RG, Hendry PJ, Starling R, de Bold MK, Ponce A, Ma KK, Williams K, de Bold AJ: Neuroendocrine profiling of humans receiving cardiac allografts. J Heart Lung Transplant 2005, 24:1046-1054.

22. Crilley JG, Farrer M: Left ventricular remodelling and brain natriuretic peptide after first myocardial infarction. Heart 2001, 86:638-642. 
23. Hunt PJ, Yandle TG, Nicholls MG, Richards AM, Espiner EA: The aminoterminal portion of pro-brain natriuretic peptide (Pro-BNP) circulates in human plasma. Biochem Biophys Res Commun 1995, 214:1175-1183.

24. Hunt PJ, Richards AM, Nicholls MG, Yandle TG, Doughty RN, Espiner EA: Immunoreactive amino-terminal pro-brain natriuretic peptide (NT PROBNP): a new marker of cardiac impairment. Clin Endocrinol (Oxf) 1997, 47:287-296.

25. Melki D, Lind S, Agewall S, Jernberg T: Prognostic value of combining high sensitive troponin $\mathrm{T}$ and $\mathrm{N}$-terminal pro B-type natriuretic peptide in chest pain patients with no persistent ST-elevation. Clin Chim Acta 2012, 413(9-10):933-937.

26. Ridker PM, Rifai N, Rose L, Buring JE, Cook NR: Comparison of C-reactive protein and low-density lipoprotein cholesterol levels in the prediction of first cardiovascular events. N Engl J Med 2002, 347:1557-1565.

27. Haverkate F, Thompson SG, Pyke SD, Gallimore JR, Pepys MB: Production of C-reactive protein and risk of coronary events in stable and unstable angina. European Concerted Action on Thrombosis and Disabilities Angina Pectoris Study Group. Lancet 1997, 349:462-466.

28. Kistorp C, Raymond I, Pedersen F, Gustafsson F, Faber J, Hildebrandt P: Nterminal pro-brain natriuretic peptide, C-reactive protein, and urinary albumin levels as predictors of mortality and cardiovascular events in older adults. JAMA 2005, 293:1609-1616.

29. Raymond I, Groenning BA, Hildebrandt PR, Nilsson JC, Baumann M, Trawinski J, Pedersen F: The influence of age, sex and other variables on the plasma level of $\mathrm{N}$-terminal pro brain natriuretic peptide in a large sample of the general population. Heart 2003, 89:745-751.

30. Redfield MM, Rodeheffer RJ, Jacobsen SJ, Mahoney DW, Bailey KR, Burnett JC Jr: Plasma brain natriuretic peptide concentration: impact of age and gender. J Am Coll Cardiol 2002, 40:976-982.

31. Troughton RW, Richards AM, Yandle TG, Frampton CM, Nicholls MG: The effects of medications on circulating levels of cardiac natriuretic peptides. Ann Med 2007, 39:242-260.

doi:10.1186/1471-2261-12-57

Cite this article as: Cui et al: Association of cardiac and renal function with extreme $\mathrm{N}$-terminal fragment Pro-B-type natriuretic peptide levels in elderly patients. BMC Cardiovascular Disorders 2012 12:57.

\section{Submit your next manuscript to BioMed Central and take full advantage of:}

- Convenient online submission

- Thorough peer review

- No space constraints or color figure charges

- Immediate publication on acceptance

- Inclusion in PubMed, CAS, Scopus and Google Scholar

- Research which is freely available for redistribution 